\title{
Cultural Circuits of Climate Change in U.K. Broadsheet Newspapers, 1985-2003
}

\author{
Anabela Carvalho $^{1 *}$ and Jacquelin Burgess ${ }^{2}$
}

\begin{abstract}
This article argues for a cultural perspective to be brought to bear on studies of climate change risk perception. Developing the "circuit of culture" model, the article maintains that the producers and consumers of media texts are jointly engaged in dynamic, meaning-making activities that are context-specific and that change over time. A critical discourse analysis of climate change based on a database of newspaper reports from three U.K. broadsheet papers over the period 1985-2003 is presented. This empirical study identifies three distinct circuits of climate change-1985-1990, 1991-1996, 1997-2003-which are characterized by different framings of risks associated with climate change. The article concludes that there is evidence of social learning as actors build on their experiences in relation to climate change science and policy making. Two important factors in shaping the U.K.'s broadsheet newspapers' discourse on "dangerous" climate change emerge as the agency of top political figures and the dominant ideological standpoints in different newspapers.
\end{abstract}

KEY WORDS: British press; climate change; cultural circuits; discourse analysis

\section{INTRODUCTION}

Research interest in media processes, products, and practices in relation to environmental issues has grown over the last 20 years or so (Schoenfeld et al., 1979; Lowe \& Morrison, 1984; Burgess, 1990; Hansen, 1993; Trumbo, 1996; Mazur, 1998; Smith, 2000) with peaks and troughs in its academic trajectory that mirror those of media coverage of environmental issues. By translating scientific knowledge into the idiom of popular discourse and amplifying risk claims, the media are key actors in public perceptions of risk (Allan et al., 2000). Citizens' awareness, attitudes, and actions toward risk are shaped, to an extent that is a matter of academic debate, by mediated information and in-

\footnotetext{
1 Departamento de Ciências da Comunicação, Universidade do Minho, Campus de Gualtar, 4710-057 Braga, Portugal.

2 Department of Geography, University College London, 26 Bedford Way, London WC1H 0AP, UK.

* Address correspondence to Anabela Carvalho, Departamento de Ciências da Comunicação, Universidade do Minho, Campus de Gualtar, 4710-057 Braga, Portugal; carvalho@ics.uminho.pt.
}

terpretations of risk (Fischhoff, 1995; Slovic, 2000). While the media may shape public risk perceptions, they also articulate public opinion and thereby play an important role in policy making, especially in sciencerelated matters (Nelkin, 1987).

Academic research on media coverage of risk emphasizes problems of inaccuracy, bias, and sensationalism in reports, advocating a style of risk reporting that offers detailed contextual information, such as explanations of uncertainty, the statistics of risk, and economic factors (Singer, 1990; Bell, 1994; Allan, 2002). However, as other studies show, the professional culture of journalism has a significant impact on risk reporting. For example, Wilkins and Patterson (1990) demonstrate the impact of typical traits of newsmaking, such as event-orientation and the dependence on official sources, in the coverage of the greenhouse effect while Boykoff and Boykoff (2004) highlight the distortion of scientific knowledge in the U.S. prestige press due to the journalistic norm of "balance." While acknowledging contributions by McComas and Shanahan (1999) and Zehr (2000), 
we believe the role of media discourse in the reproduction and transformation of scientific and political claims in relation to dangerous climate change merits more attention.

In this article we first outline the elements of a cultural-political theoretical approach to understanding the production and consumption of media representations of climate change, before turning to an indepth case study based on analysis of 19 years' coverage of climate change in a sample of the U.K.'s broadsheet newspapers (Carvalho, 2002, 2005). The article will argue that the mass media play a central role in the social construction of risk. Different social actors (scientists, politicians, policymakers, businesses, pressure groups, and media professionals) are locked in discursive competition around how climate change risk is to be framed in the media. Our critical discourse analysis (CDA) reveals that political actors have played by far the most powerful and effective role in shaping climate change in the public sphere over the last 20 years, but their framings have always been mediated through each newspaper's preferred ideological worldview.

\section{UNDERSTANDING MEDIA CONSTRUCTIONS OF RISK: MODELING CIRCUITS OF CULTURE}

Although media studies have largely rejected a linear, transmission "cause-effect" model of mass communications-in which (dominant) producers transmit messages across space and through time to (subordinate, passive) receivers-the "information model" has remained an influential framework in studies of science communication. The approach can be seen to underpin "the canonical view," which typically conceptualizes science communication as "popularization" of learned academic findings for lay members of the public (Bucchi, 1998; Allan, 2002). How does a cultural-political perspective differ? By offering an alternative conceptual framework that recognizes the profound significance of mass media in contemporary life. Traditional print and broadcast media, embracing new information and communication technologies, play a central cultural role in modernity through the selective provision of social knowledge, including that of science and technology; attempts to forge consensus about the natural order of events and actions, including risk, through continual redefinitions of reality; and a continuing struggle for legitimacy between differentially empowered groups through discursive means (Hall, 1977, 1980;
Fairclough, 1995; Curran \& Gurevitch, 2000). As the seminal book by Douglas and Wildavsky (1982) reminds readers, different cultural perspectives arising from different forms of social relations play a fundamental role in constructing risks as well as the procedural rationalities through which those risks are addressed (Dake, 1992; Adams, 1995). But in the emphasis on typologies of risk in culture theory, equally important questions about how risks are constructed within different systems of signification have often been submerged. One valuable contribution made by Beck (1992), for example, was to emphasize the power of media communications in shaping cultural politics in the era of "global mega-hazards" such as climate change.

In British cultural studies it is possible to find a conceptual framework for studying social constructions of risk that understands culture "as a social product with its own forms of objective existence and its own real shapes" (Johnson, 1986, p. 282). The model known as the circuit of culture has semiotic processes of "encoding" and "decoding" meanings in verbal and visual texts, constrained by contextual factors, at its heart. Through the application of linguistic-, visual-, and genre-based rules, media professionals produce texts that circulate-and help define-the public sphere (Habermas, 1989; Hall, 1980). Audiences, through their own meaning-making practices, decode media communications in the contexts of their everyday lives: "readings" that may or may not accord with the framings offered by the media (Morley, 1986; Burgess et al., 1991). In its original formulation, the circuit of culture is not able to address issues of reflexivity: over time, political and economic contexts change as do scientific knowledge claims and popular understanding of what constitute environmental risks. Fig. 1 represents our adaptation of the model to allow for analysis of media constructions of risk through time.

The model distinguishes between three key "moments" that fold into one another: production, textual analysis, and consumption, leading to new moments of production. Taking production first, groups of media professionals work in contexts structured by institutional, economic, political, and technological demands to produce stories from source materials that will define the day's news. Depicting the environment posits various challenges for media professionals (Wilkins \& Patterson, 1990; Hansen, 1993; Bell, 1994; Anderson, 1997; Smith, 2000). Time-scales, spatial categories, and causal links in issues such as climate change are not immediately compatible with 


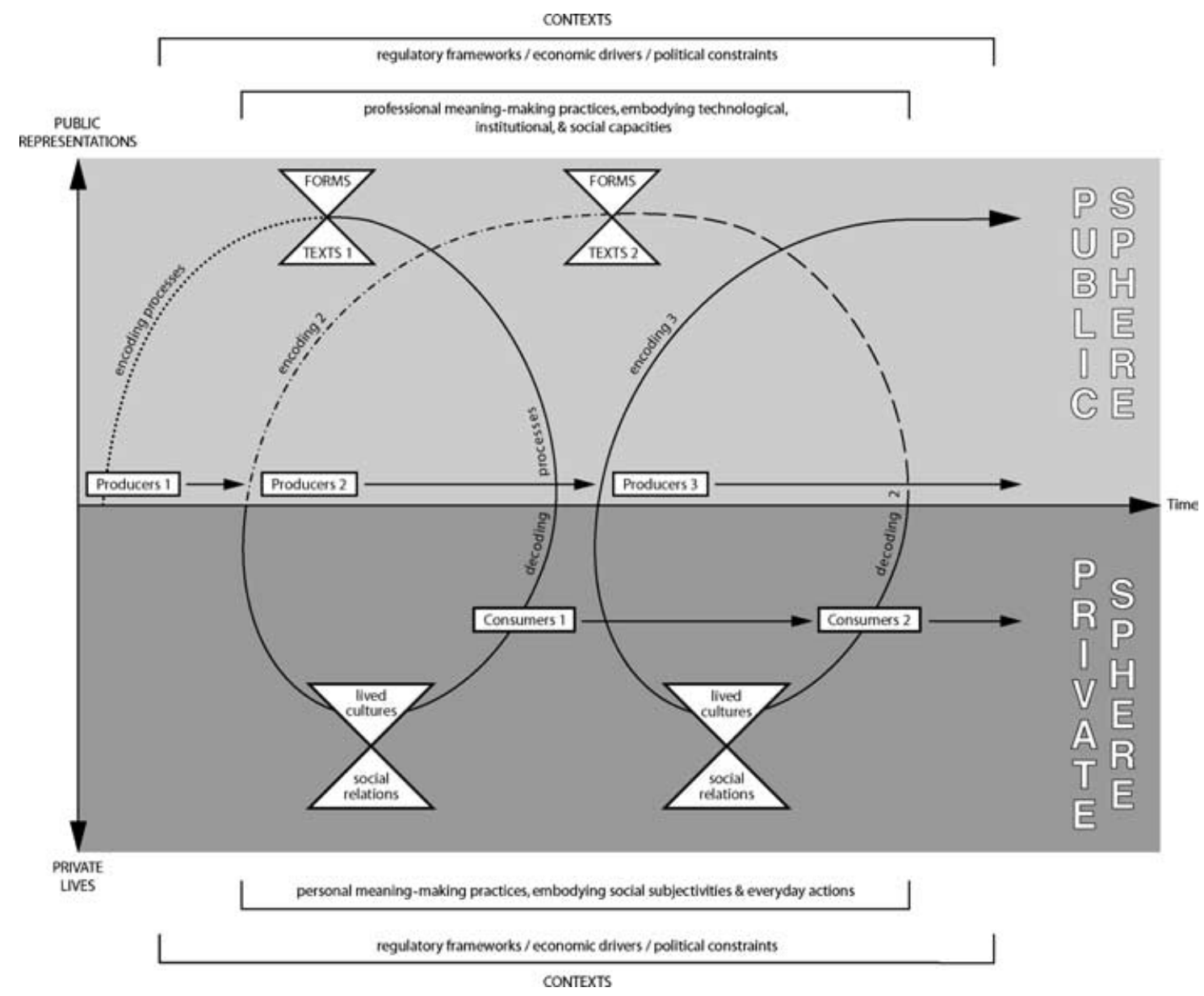

Fig. 1. A diachronic model of circuits of culture (developed from Johnson, 1986; see Du Gay, 1997 for different formulation).

conventional news values, such as novelty, recency, and factuality. The complex and "diffuse" nature of the problem leaves scope for media sources to have a very influential role in shaping media agendas and discourses on this issue (see Gandy, 1982). The media apply a number of standard principles, procedures, and routines (Gandy, 1979) both to the initial selection of events that will become "news," and to "encode" the source material. Of particular importance, the producers have a strong sense of their putative audience, and how the story should be told.

The second moment identified in the circuit is the public dissemination of encoded messages either as nonmaterial electronic broadcasts on television, radio, or the internet, or as material printed newspapers, magazines, and so forth. The texts for analysis thus include linguistic, aural, and visual communications, enabling analysts to deconstruct the discursive rules in play (Burgess, 1985, 1990; Myerson \& Rydin,
1996; van Leeuwen \& Jewitt, 2001) and their rhetorical functions such as how linguistic texts and visual images seek to persuade audiences of their facticity or truthfulness (van Dijk, 1988; Fairclough, 1995). Producers endeavor through the rhetoric of their verbal and visual communications to position readers and viewers so that they interpret texts in the ways intended, and clearly there are asymmetries in terms of the power that encoders can exercise in framing knowledge claims and what significance they might have. However, as the corpus of qualitative research with audiences (the third moment) who consume media products shows, readers also have power in resisting or subverting preferred interpretations (Myers \& Macnaghten, 1998; Corner, 2000). Meanings are remade in the contexts of social interaction at the local level as media texts are reembedded in daily life. While this argument holds for a wide range of cultural products, there are particular issues 
associated with complex scientific knowledge claims and the competencies of audiences to engage critically with such discourses (Irwin \& Wynne, 1996; Ungar, 2000), which may well, for specific policy purposes, require more structured processes of social interaction between lay and specialist audiences to provide spaces for deliberation (Burgess et al., in press).

Audiences for media products are not only socioeconomically but also culturally differentiated (Bourdieu, 1984). Specialists, including climate change scientists and media workers, are also potentially powerful audiences-powerful in the sense that they do have the capacity to help shape new phases of production. New strategies emerge such as evolving editorial stances in relation to the issue; new research grants because of the high profile of certain research teams in the media; new opportunities to construct a public relations campaign; new pressures for more or less regulation to encourage eco-efficiencies; new ways of making scientific publications more "media friendly," and so on. In the biography of climate change risks, some of these "mediatization" strategies are now clearly visible such as changing relations between scientists, policymakers, and journalists (Mormont \& Dasnoy, 1995; Weingart et al., 2000). By studying representations of climate change diachronically, it becomes possible to identify some of these influential relationships.

\section{RESEARCHING CULTURAL CIRCUITS OF CLIMATE CHANGE}

Conducting empirical research that attempts to hold the whole circuit together through longitudinal research with journalists and their sources, quantitative and discursive textual analyses on the multiplicity of print and broadcast texts in circulation over the same time-scale, and ethnographic research with different audiences is extremely challenging (Burgess \& Harrison, 1993) although vital if social constructions of risk are to be properly understood. In the case study presented here, emphasis is given to a detailed discourse analysis of media texts but over a substantial length of time, enabling us to identify three phases of development in the cultural construction of climate change risks. A few contemporaneous studies with U.K. producers (Chapman et al., 1997; Anderson, 1997; Smith, 2000) and audiences (Harrison et al., 1996; Hinchliffe, 1996; Myers \& Macnaghten, 1998) do exist but, frustratingly, are not directly comparable with the work presented here.
Newspaper production and consumption in the United Kingdom are polarized: at the national level, there are a small number of what were known until recently as "broadsheet" or "quality" newspapers characterized by extensive political and economic comment, which have relatively small but welleducated and influential readerships (The Times, The Guardian, The Independent, Daily Telegraph, Financial Times, and weekend stable-mates). The remaining newspapers are often labeled "red-tops" with a more populist orientation including greater emphasis on crime, sex, and celebrity (Daily Mail, Daily Express, Daily Mirror, Sun). The analysis presented here focuses on The Guardian (and the Sunday broadsheet The Observer), The Independent (including The Independent on Sunday), and The Times (including the Sunday Times). The choice of newspapers results from interest in examining, as fully as possible, developments in the arguments and perspectives of various social actors on climate change. Debate is excessively simplified or excluded in other media. Furthermore, the selected newspapers have an important power of "agenda-setting" for decisionmakers, politicians, the public, and the other media in the United Kingdom (Sparks, 1987). These newspapers span over the political spectrum and were selected to represent different editorial positions: The Guardian is owned by a charitable trust, represents liberal, social democratic politics, and has long played an active role in covering environmental issues; The Times has a conservative, right-of-center editorial policy committed to the "establishment" and the sovereignty of traditional institutions. Finally, The Independent is a new broadsheet paper established in 1986 without any declared partypolitical line.

The main questions we want to address are the following: How has the press represented risk associated with climate change in the last two decades? How have the claims and views of different social actors been reconstructed in newspapers? In what ways do media texts relate to the wider sociopolitical context in which they are produced and consumed? CDA provides the theoretical and methodological approach to examine these issues. The circuit of culture concept offers a general framework for the social construction and reconstruction of reality; CDA offers in turn specific analytical tools for the deconstruction of meanings. A concern with the significance of language practices, especially verbal ones, in the construction of meaning is common to the many strands of discourse analysis (see Schiffrin, 1994). Distinctively, CDA links language use to the 
particular social and political contexts in which it takes place (e.g., Fairclough, 1995; van Dijk, 1988; Wodak et al., 1999). Discourse is viewed as a form of social practice and each discursive event is both influenced by social life and constitutive of new forms of thinking and relating to the social world. Instead of analyzing texts per se, CDA attempts to understand the links between texts and social relations, distribution of power, and dominant values and ideas. As we have argued, media texts encapsulate the social contexts in which they are produced and shape people's readings of and acting upon the world. This, in turn, motivates a new cycle of production of texts.

The analytical framework used here addressed both texts and contexts. At the textual level, the following issues were considered: morphological characteristics (i.e., related to form or position-size of the article, position, section) and structural organization of texts (what is chosen for the headline and the first few paragraphs, what is left for the end of the text); objects (themes) and actors represented in the text; linguistic and rhetorical issues (lexical choices, metaphors, and other figures of speech); discursive strategies (strategies of discursive "manipulation" of reality in order to achieve a certain goal or effect); and ideological standpoints (the ideas, values, and worldviews associated with particular forms of "talking" about reality). Discursive strategies and ideological standpoints can be inferred from the analysis of the other elements and their interaction in the construction of particular meanings. By looking at how a particular choice of words, for instance, is recurrently associated with a certain social actor we can start to identify the discursive strategy of the "speaker" with regard to that actor (e.g., legitimation of a given action or discrediting). More generally, we have to pay attention to the overall meaning effect created in the text in relation to an issue or actor. Obviously, discussing all these issues in detail for all the articles that were analyzed is not viable within the limits of this article.

Contexts were addressed both through reference to key events in climate change science and policy over the period, as well as a more general review of changing economic, political, and social events in the United Kingdom over the period. The contextual analysis runs along two axes: comparative-synchronic (simultaneous depictions of the issue in different newspapers) and historical-diachronic (temporal sequences and evolutions).

CDA is essentially an interpretive work. Logic and credibility of argumentation, backed up by quotes from the texts, are the main "validity" tests in this kind of analysis (see Lincoln \& Guba, 1985; Potter, 2003).

\section{CONSTRUCTING DANGEROUS CLIMATE CHANGE}

The set of press articles to be analyzed was put together with the results of keyword searches on the newspapers' CD-ROMs, and the FT-Profile and Lexis-Nexis databases for the period January 1, 1985 to December 31, 2003. The keywords were climate change OR global warming OR greenhouse effect. Given that search results included many articles where climate change was merely referred to in passing, the initial database was narrowed down to those articles where it was the core (or associated with the core) theme. This required a scan-type reading of all the texts to select those where climate change was mentioned in the headline; references to the topic filled a significant part of the article; climate change was presented as the cause of the central theme (such as an extreme weather event); or "solutions" for it were discussed. ${ }^{3}$ A total of 5,910 articles met at least one of these conditions. Fig. 2 shows their distribution in time.

The volume of press coverage provides an important indication of the attention given to an issue over time. Fig. 2 shows three main phases to date: 1985-1990, when media attention to climate change rises significantly; 1991-1996, a period of recession in the volume of coverage; and 1997-2003, a second sharp rise (although marked by some fluctuation). This division into three main periods is also sustained by discourse analysis of news articles, which showed, as discussed below, that important modifications in the meanings associated with climate change also occurred in those segments of time.

All the articles published between 1985 and early 1989 were subjected to a detailed discourse analysis. From January 1989, a process of discursive "sedimentation" was detectable, as various discursive strategies and standpoints started to appear recurrently in press reports. From this period, the analysis was focused on critical discourse moments (Chilton, 1987; Gamson, 1992), marked by relevant events related, for instance, to political or scientific activity, such as international summits or the launch

\footnotetext{
${ }^{3}$ For the period 2001-2003, instead of doing this type of selection, figures of "core" articles have been calculated from the initial keyword search results based on the percentage of articles selected in the previous periods.
} 


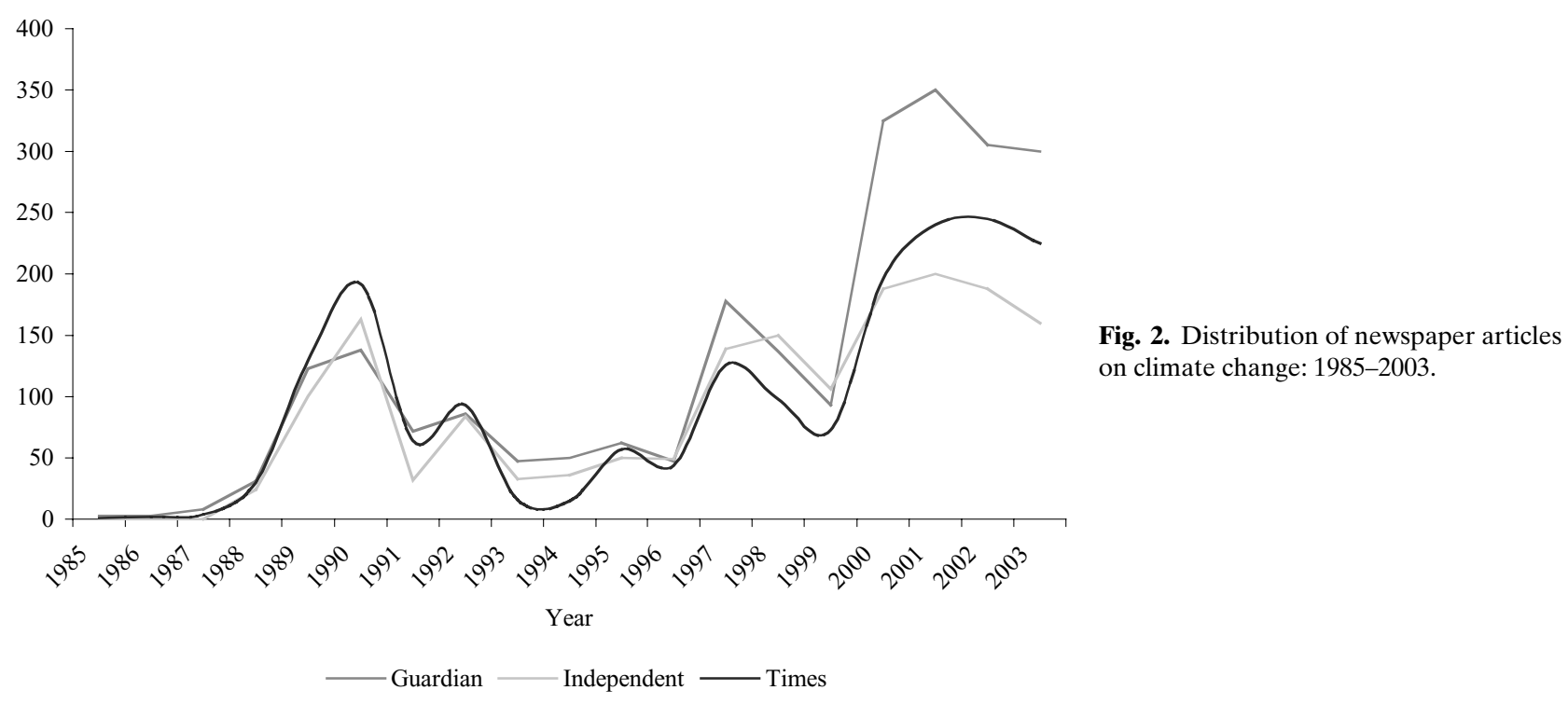

of reports of the Intergovernmental Panel on Climate Change (IPCC). These critical moments entail a potential for transformation in understandings of a problematique and constitute a test for "established" discursive positions. Therefore, it is important to examine whether and how representations of the greenhouse effect changed or remained static in these moments, which are pointed out below.

\subsection{5-1990: From Silence to the Political Construction of Risk}

Between 1985 and 1990 the discursive construction of climate change in the British press underwent an important transformation as the early definitional power of scientists was usurped by the direct intervention of the British Prime Minister, Mrs. Margaret Thatcher, in the debate, toward the end of 1988. Between 1985 and 1988, The Guardian and The Times depicted scientific knowledge on the enhanced greenhouse effect as consensual and reliable, relying on scientists and mainstream science journals as major sources. Given news preferences for a novel news subject and to meet the need for clarity and lack of ambiguity, the scientific claims were simplified to be understood by a general audience and "strengthened" to fit the media's rhetorical purposes. Scientists were the exclusive definers of the issue for the press but their capacity to influence the media agenda-and therefore the public and political agendas-remained very limited as suggested by the number of news articles. While early press representations of climate change exhibited a strong degree of confidence in the forecasts of a "major global warming" they did not show any traits of catastrophism (cf. Weingart et al., 2000). Rather, the press clearly underestimated the risks associated with climate change, and refrained from presenting its possible consequences. In a similar vein, newspapers remained silent about responsibility for the problem, not only leaving unquestioned the economic and social practices that generate greenhouse gases (GHGs) but also omitting references to the role of political institutions.

The turning point in media discourse on climate change was Mrs. Thatcher's speech to the Royal Society on September 27, 1988 when she stated that: "It is possible that ... we have unwittingly begun a massive experiment with the system of the planet itself." The impact of her intervention has been widely commented upon and the sharp rise in the volume of subsequent press coverage on the greenhouse effect clearly indicates the weight of political leadership in the definition of risks. After Thatcher's speech, climate change was often narrativized as a major risk for human security. Stronger scientific claims were amplified; for the first time, scenarios of impacts were brought forward. The Independent, which had remained largely silent about the problem, started magnifying it. On October 17, 1988, for example, a front-page headline announced that the "Met Office predicts global-scale floods." A temperature rise of $5.2^{\circ} \mathrm{C}$ was forecast for the following $50-100$ years, a 
much higher estimate than those of most scientists at the time. The Times also presented global warming as a substantial danger at the end of 1988. The strategy of dramatization of the problem is clear in headlines like "Upheaval to climate "imminent"" or "Can we stop Britain drowning," 5 and in a significant number of other articles.

As the range of political measures, economic transformation, and lifestyle adaptations necessary to address climate change became evident, The Times shifted to a more skeptical position. Skepticism in relation to scientific claims on climate change was promoted by emphasizing the lack of evidence and the exaggeration of the problem by the other media. In "The final forecast?; The world's weather," Brian James (November 11, 1988) maintained that "when challenged by the decision-makers ... the climatologists lack all proof." From a different ideological stance, The Guardian maintained its emphasis on the risk associated with climate change. Its science correspondent Tim Radford was highly critical of government announcements such as the proposal by Mrs. Thatcher and her Environment Secretary Nicholas Ridley that nuclear power was a good option to address the greenhouse effect. ${ }^{6}$ In The Independent some authors appeared to align with the government's discursive construction of climate change but others showed a more critical attitude. The Independent's science correspondent, Nicholas Schoon, for example, reported on the views of "experts" to counteract Thatcher's and Ridley's strong promotion of nuclear energy as a means of decreasing GHG emissions. ${ }^{7}$ Interestingly, the debate on whether nuclear power should be promoted reignited in the U.K. press in the summer of 2004-led by The Independent - as the risks of an "energy-crunch" grew more substantial.

The social construction of risk acquired new agents from among the elite audiences of the media at this time. As climate change gained political significance, various political actors attempted to interpret scientific claims and use different studies to promote different arguments and agendas. In 1989-1990, Mrs. Thatcher continued to shape the public construction of risk associated with climate change. Her speech at the United Nations (November 8, 1989) framed global environmental change into the main risk

\footnotetext{
4 Robert Mathews, November 14, 1988.

5 Peter Davenport and John Young, October 21, 1988.

6 "The edge of darkness," November 2, 1988; "The dread and the green," November 22, 1988.

7 "Experts see better ways to counter global warming," Nicholas Schoon, November 7, 1988.
}

facing humanity: "It is life itself that we must battle to preserve"; "The challenge for our negotiators is as great as for any disarmament treaty." ${ }^{8}$ Her rhetorical strategy may be described as "securitization" (Wæver, 1995), representing climate change risks as "an existential threat" to the future of the planet (Stripple, 2000 , p. 2). The ideological lines were drawn between a neo-liberal politics, which framed climate change as a global threat that required every country to share the burden, and a more radical politics, which argued that mitigation/adaptation costs should be borne by the industrialized nations most responsible for the production of GHGs.

Another critical moment was the public presentation of the first IPCC science report on May 25, 1990. Noncoincidently, Mrs. Thatcher opened the Hadley Centre for Climate Prediction and Research and announced the British target for GHG emissions on the same day. In both The Independent and The Guardian, the IPCC report was an opportunity to emphasize a sense of danger, with headlines such as: "The greenhouse time bomb: Authors of UN report say new data shows they have underestimated dangers of global warming." A precautionary approach was advocated in both newspapers, but The Guardian had a more politically motivated approach to climate change, regularly criticizing official positions or policies.

Reflecting a very different ideological position, the Sunday Times carried a series of articles stimulated by the publication of the IPCC report that crudely scorned environmental concern and dismissed the problem of climate change: "Green hysteria sets red alarm bells ringing"; "Global Fawning. Global Warming" (May 27, 1990); and two editorials entitled "Greenhousemongers" (May 27, 1990) and Greenhousemongers 2 (June 3, 1990). A rhetorical strategy of de-legitimating unwelcome scientific or political knowledge claims by discrediting the agents of such claims was common in The Times' coverage: "sentimental ululation," "mysticism," and "green Stalinism" are some of the labels employed by The Times about "environmentalists" and "environmentalism," categories that appear to subsume everyone from scientists to environmental NGOs. The newspaper's loyalty to the Conservative government, which was pushing an image of danger associated with climate change to create "discursive space" for advancing particular policies, was in tension with The

\footnotetext{
8 "Thatcher in call to save environment," Martin Walker, The Guardian, November 9, 1989.

9 Steve Connor, May 27, 1990, The Independent.
} 
Times' allegiance to values of individual freedom, free market, and the preservation of the status quo. In this period, the paper's core values were dominant in its discourse. It was prominent in reporting the U.S. climate change "backlash," financed by business and pursued in conservative think-tanks, and giving voice to the powerful self-promotion activities of the "skeptical" scientists.

Between 1985 and 1990, climate change scientists first gained and then lost definitional control of what climate change was and what it meant for the world. Similar findings have been reported in the United States (Trumbo, 1996) and Germany (Weingart et al., 2000). British media only took a "Cassandra role" (Weingart et al., 2000) after the enhanced greenhouse effect was embraced by the Prime Minister: the discursive construction of climate change into a public risk was clearly tied to the government's initiative to situate that risk within a neo-liberal economic program, sharing the costs globally while reaping potential economic benefits nationally. This framing served to highlight profound ideological differences between the three broadsheet newspapers' representations of scientific knowledge claims: discourses were transformed as scientific uncertainty was used to sustain different value-based positions with regard to what should be done.

\subsection{1-1996: Climate Change Recedes in the Public Sphere}

As shown by Fig. 2, U.K. national press coverage of climate change declined sharply in 1991. Despite small recoveries in 1992 (Rio Earth Summit) and 1995 (1st Conference of the Parties for the United Nations Framework Convention on Climate Change (UNFCCC)-COP-1), levels of attention remained low until 1997. Thus, there is little correspondence between scientific knowledge of climate change risk and media understanding of that risk: levels of GHGs continued to rise and the 1995 IPPC report strengthened risk claims in relation to anthropogenic impacts on the climate. Several factors may explain why, from 1991, the British press's representations of risk associated with climate change faded away: following extremely high levels of coverage of environmental issues in the late 1980s, editorial "fatigue" set in, not least because no "climate catastrophe" occurred and it became difficult to sustain a "dramatic" risk storyline (see Ungar, 1992, 1995; McComas \& Shanahan, 1999 for similar findings in the U.S. press); a lower political profile of the environment (e.g., there were no significant public pronouncements by political leaders on climate change in 1991); the onset of economic recession in the United Kingdom meant a loss of advertising revenue for newspapers and a general political downgrading of the environment in relation to other more traditional economic and social concerns; and the realization of the "cost of significant progress" (Downs, 1972). The UNFCCC was signed at Rio in 1992 but generated little sustained press coverage over the next three years. In the public sphere, the dangers posed by climate change effectively "disappeared." Quantitative surveys of U.K. public opinion recorded a decline in importance attached to climate change risks (Rudig, 1995) while qualitative research revealed considerable uncertainty among members of the public about what climate change meant, whether it was a current or future threat to human and ecological well-being, and how it related to the emerging policy discourse of "sustainable development" (Harrison et al., 1996; Hinchliffe, 1997; Macnaghten \& Jacobs, 1997; Burgess et al., 1998).

In late 1995, two critical moments witnessed some increase in coverage: COP-1 in Berlin and publication of IPCC's Second Assessment Report. The IPCC's report (IPCC, 1996) ${ }^{10}$ clearly stated for the first time that human activities have an impact on climate: "the balance of evidence suggests a discernible human influence on global climate." The report also called for stricter mitigation measures for GHG emissions. Reconstructions of scientific claims in the press in this period varied considerably and the role of the different ideologies espoused by news professionals was clear. While The Guardian ${ }^{11}$ and The Independent ${ }^{12}$ amplified the risks and mobilized public concern about climate change, The Times attempted to discredit the IPCC. ${ }^{13}$ Again, reflecting different ideological positions in relation to the issue, interpretative differences can be detected in newspapers' expectations and evaluations of COP-1, whose purpose was to strengthen the goals set up by the UNFCCC. The Guardian, and to a lesser degree The Independent, attempted to keep climate change risk on the public agenda. The Times sought to persuade its readers that climate change did not pose any significant risk to society. For example, several articles clearly demonstrate what Dryzek (1997) calls a "Promethean Discourse," conceiving

10 The report was released at the end of 1995 and published in 1996. 11 For example, "Climate: A race against time," Paul Brown, December 5, 1995.

12 For example, "Global warming is here, experts agree," Nicholas Schoon, p. 3, November 30, 1995.

13 "The heat of argument," Nigel Hawkes, October 30, 1995. 
no limits to the exploitation of nature for material development and economic growth. ${ }^{14}$ This ideological standpoint was also present in The Independent, often coupled with a neo-liberal position..$^{15}$ As opposition to state regulation led some to deny the risks involved in climate change, other authors in The Independent amplified those risks and raised concern. ${ }^{16}$

The discursive strategy of simply denying the risk was challenged by the first appearance of an important commercial actor as the global insurance industry publicly supported the climate science-policy community. Threatened by very large losses resulting from climate-change-related events, the insurance industry demanded political commitment to a precautionary approach. By framing the problem in financial terms, insurers eased access to some conservative fora, like The Times. ${ }^{17}$ The industry's intervention demonstrated division among powerful business interests in relation to climate change and therefore helped to redefine the economic stakes of the issue. As Greenpeace entered a "discourse coalition" (Hajer, 1995) with the insurance industry it also advanced its own agenda (Leggett, 2000), adjusted to resonate with other publics.

In this second circuit, there are therefore some observable differences in the discursive construction of climate change. Partly such changes may be explained by editorial demands for a new angle (Downs, 1972; Gans, 1979) but it is also evident that journalists were learning from their ongoing engagement with climate change scientists and policymakers. Environment correspondents such as Nicholas Schoon (The Independent), Paul Brown ${ }^{18}$ (The Guardian), and Nick Nuttal (The Times) had been covering climate change since the late 1980s, experiences reflected in their framing of many stories at this time. There is a discernible shift from asking basic questions about the science to exposing the political games and pressures that may shape the outcomes of the sci-

\footnotetext{
14 "Save the world: vote for an econut," Norman Macrae, Sunday Times, April 2, 1995; "Beware of the greens who cry wolf," Matt Ridley, March 25, 1995.

15 "Global warming won't cost the earth," Frances Cairncross, March 27, 1995.

16 "Threat of global warming to grow faster," Nicholas Schoon, March 21,1995; "Global warming puts Britain's climate down the plughole," Geoffrey Lean, The Independent on Sunday, March 26, 1995 .

17 For example, "Insurers support green reforms at Berlin summit," Nick Nuttall, March 27, 1995.

18 Brown (1996) subsequently published a book on climate change science policy.
}

ence production process. ${ }^{19}$ Journalists used this "antiblackboxing" strategy as a form of reinforcing trust in what the IPCC put forward, despite all the conditioning mechanisms exerted over it.

In summary, specific social, political, and economic contexts impacted on discursive practice in the early 1990s. As a set of circumstances constrained the production of media representations of climate change, and as the "consensual" discourse of "sustainable development" came to be dominant in policy circles, it seems likely that policymakers may have had more leverage to make nonnecessary choices, which the media sanctioned. Government opposition to the carbon tax proposed by the European Union in 1993, which could have had significant environmental benefits, and the missed opportunities in the U.K.'s Climate Change Programme published in 1994, for example, received very little coverage. As the international agendas of climate change science and politics moved forward in 1995 and as new social actors, such as the insurance industry, actively proposed new readings of climate change, media discourse also regained some momentum.

\subsection{7-2003: Danger Comes Close to Home}

The analysis presented so far was extended to 2003 for the purposes of this article but we can only briefly cover this most recent cultural circuit. It is marked by a different discursive strategy in which the dangers of climate change are being realized in specific geographical places and events. In 1997, after nearly two decades of Conservative government, New Labour, under Prime Minister Tony Blair, took power. Not traditionally a political party associated with strong environmental interests, there were nevertheless hopes that the active role played by Conservative Environment Minister John Gummer in preparing the U.K. case for Kyoto in late 1997 would be continued under New Labour. The substantial increase in volume of press coverage (Fig. 2) marked the political significance of $\mathrm{Kyoto}^{20}$ and increasingly explicit calls for action by IPCC in the Third Assessment Report (2001).

\footnotetext{
19 For example, "The right climate for tax on fuel," October 16, 1995, and "Global warming is here, experts agree," p. 3, November 30, 1995, both by Nicholas Schoon, The Independent; "World's burning issue," October 28, 1995, Paul Brown, The Guardian.

20 Kyoto has also been the news peg behind dramatic rises in media coverage in the United States (Shanahan, 2000).
} 
Oppositional cultural politics-in the sense of active conflicts between different ways of framing the societal problems generated by climate change-were subdued in the public sphere from 1997 to 1998. The promise that sustainable development could be achieved through new styles of governance where all parties willingly negotiated for "win-win" outcomes fitted New Labour's larger political ideology for partnerships between the state, the market, and civil society (Munton, 2003). The scope for the press to invigilate and challenge the politics of climate change narrowed in the immediate post-Kyoto period, before the papers were able to identify opportunities to reassume their more traditional discursive positions. From late 1998, the press appeared to be more alert and there was more critique of New Labour, especially in The Guardian, which started once more to goad national government for failing to act on environmental issues, including climate change, ${ }^{21}$ while The Times promoted business interests, privileging policy options that served the most powerful industries. ${ }^{22}$

Representations of the climate science-policy nexus in 1997 showed definite signs of social learning having taken place. There was an increased tendency for news professionals to talk about "backstage" issues like the interests and commitments of actors involved in science-making, contributing to a more in-depth understanding of the international politics of climate change. ${ }^{23}$ While, as argued above, this shift may be seen as merely reflecting editorial demands for "new angles" on climate change, there was, unusually, an increased reflexivity in news discourse. The role of the media in relation to the social and political status of the environment generally, and climate change particularly, was discussed in some articles and some journalists openly reasoned about their own personal commitments to the issue. ${ }^{24}$

One notable feature of more recent discourse since 1999-2000 is a new sense of urgency attached to risks from climate change. Rather than being represented as a remote possibility for distant "others," the impacts of climate change are brought into audiences' everyday experience by news professionals reporting dramatic weather-related events in the discursive

21 For example, "The Thatcher legacy: Behind the mask," John Vidal and Paul Brown, September 30, 1998.

22 For example, "Levy to benefit public sector but hurt industry," Carl Mortished, June 30, 1999.

23 For example, "Getting warmer, but still a long way from our goal," Nicholas Schoon, The Independent, December 12, 1997.

${ }^{24}$ For example, "Last night's TV: You don't want to do that," Desmond Christy, The Guardian, December 12, 1997. frame of accelerating climate change. Two examples of "critical discourse moments" are the severe riverine flooding in autumn 2000, and the 2003 heat wave when many parts of Europe registered their highest ever summer temperatures. ${ }^{25}$ Causal links between these extreme "natural events" and climate change were prominent in press reports, an interpretive tendency reinforced by senior government politicians ${ }^{26}$ perhaps keen to deflect attention from other, more immediate potential contributory factors such as inadequate planning controls over development in floodplains and changing farming practices. The Times, as in previous years, still attempted to dismiss climate change $^{27}$ as a real risk but, given growing consensus that extreme events and abrupt weather changes could be manifestations of an increasingly unstable global climate, was forced to moderate its tone.

Extreme natural events such as floods and heat waves have long provided media with dramatic, newsworthy stories. As in 1987-1988 in the United States, when a summer heat wave stoked early greenhouse effect stories (Ungar, 1992; Mazur, 1998), the extreme weather events of the last few years provided an excellent hook for the new interpretive round of stories. Amplifying the new cultural understanding that unusual/extreme weather events were being "caused" by climate change were increasing numbers of climate change scientists turning to regional assessments of climate change impacts and the IPCC's shift toward emphasizing regional impacts of climate change in its public communications strategy. Senior U.K. policy actors such as Sir John Houghton (former head of the Meteorological Office) and Sir David King, the Government's Chief Scientist, made headlinegrabbing interventions by attempting discursively to map the dangers of climate change in the issue-arena (Hansen, 1993) of terrorism and national security. As The Guardian reported in July 2003:

25 For example, "Global warming is now a weapon of mass destruction: It kills more people than terrorism, yet Blair and Bush do nothing," John Houghton, July 28, 2003; “Action stations," John Schellnhuber, August 6, 2003; "Extreme weather: Global warming may be speeding up, fears scientist," John Vidal, August 6, 2003 (all articles in The Guardian); "Britain braced for a Sunday roasting," Robin McKie and Mark Townsend, The Observer, August 10, 2003.

26 For example, "Weather: 'action now essential': Extreme events will be the norm-Prescott," Paul Brown, The Guardian, p. 1, November 1, 2000.

27 For example, "Britain can cope, whatever the weather," leading article, October 31, 2000; "This folly of a policy is powered by windy thinking," Philip Stott, July 15, 2003. 
Warning voices, carrying the threat of a future dystopia, are becoming clearer and more insistent.... Two weeks ago Sir John Houghton, the former head of the Met Office, compared climate change to a weapon of mass destruction. ${ }^{28}$

Signaling a new interpretive strategy that may well have important future ramifications, the risks from accelerating climate change prompted debate in the U.K. media about the merits of embracing a new nuclear power program to generate electricity. Raised in The Times in summer $2003,{ }^{29}$ the debate grew during 2004 stimulated by The Independent, which devoted an entire front page to James Lovelock's ${ }^{30}$ conclusion that nuclear energy production was "the only green solution" able effectively to mitigate climate change. The stage is set in the United Kingdom for a fascinating cultural-political struggle over the next few years between deeply engrained public understandings of dangerous nuclear power and much more shallowly embedded framings of dangerous climate change (Burgess et al., 2004).

\section{CONCLUSIONS}

The case study presented here is framed as a series of cultural circuits and highlights the need for research to address seriously the social dynamics of communicative processes in relation to present and future actions to mitigate the impacts of climate change. Risk, as Douglas and Wildavsky argued so convincingly, is socially constructed and as such, the mass media play an important role in delimitating "the social limits to curiosity" (1982, p. 102) for all the actors brought into relationship. Research has demonstrated that media representation is an important agenda-setting factor for audiences in relation to "unobtrusive" issues such as climate change and, more importantly, is a significant influence in shaping people's knowledge and perceptions of the issue (Wilson, 1995; Krosnick et al., 2000; Ungar, 2000; Corbett \& Durfee, 2004).

This analysis of 19 years of discourse on climate change provides insight into how cultural-political circuits are functioning. The analysis shows that the broadsheet print media are responsive to scientific and social learning, to changing political agendas and contexts, and to the communicative strategies of

\footnotetext{
28 "The climate must change: And reform must start with America," Leader, August 6, 2003.

29 'Nuclear power 'is critical to Britain's future,' Mark Henderson, August 18, 2003; "Making the case for nuclear power," nonattributed, August 21, 2003.

30 "James Lovelock: nuclear power is the only green solution," The Independent, May 24, 2004.
}

agencies such as IPCC, as long as those responses complement, or can be made to complement, each newspaper's editorial position. Values and ideological cultures are key to explain variations in the media's reinterpretations of scientific knowledge on climate change, which in turn may either sustain or annihilate the space for particular options for policy making and individual action. While some media may legitimate and consolidate particular policies, others have had a crucial role in drawing attention and building concern for climate change, as well as in contesting political choices and showing that there are alternative courses of action. In an early study of the U.S. press coverage of climate change, Wilkins (1993) found that the values of "progress," "innocence," and the "institutionalization of knowledge" in scientific and governmental bodies were important in framing climate change in a way that promoted technological "fixes" and de-emphasized ethical and political choices.

Besides constructing particular images of reality, media discourse also constructs social actors into particular roles, statuses, or positions. The credibility that the broadsheet newspapers assigned to claimsmakers, and most prominently to the IPCC, was radically divergent between the papers and was sustained over the period. Given that the audiences of the broadsheet papers are themselves highly segmented sociodemographically, culturally, and politically, this analysis suggests that a more nuanced reading of public trust in science and scientific institutions, as well as the social and political power of such institutions, is necessary.

The article has shown that coverage of climate change has been strongly linked to the political agenda on this issue, and particularly to public pronouncements and discursive strategies of prime ministers and other top governmental figures. Furthermore, as noted above, our analysis indicates that the media build particular images of scientific knowledge and uncertainty on climate change, and emphasize or de-emphasize forecasts of impacts, in order to sustain their political preferences regarding the regulatory role of the state, individual freedom, and the general economic and social status quo. Dangerous climate change is thus both politically defined and ideologically constrained.

\section{ACKNOWLEDGMENTS}

Anabela Carvalho would like to acknowledge the financial support of Universidade do Minho and Fundação para a Ciência e Tecnologia for the research that led to this article. 


\section{REFERENCES}

Adams, J. (1995). Risk. London: UCL Press.

Allan, S. (2002). Media, Risk and Science. Buckingham: Open University Press.

Allan, S., Adam, B., \& Carter, C. (Eds.). (2000). Environmental Risks and the Media. London and New York: Routledge.

Anderson, A. (1997). Media, Culture and the Environment. London: UCL Press.

Beck, U. (1992). Risk Society: Towards a New Modernity. London: Sage.

Bell, A. (1994). Climate of opinion: Public and media discourse on the global environment. Discourse \& Society, 5, 33-64.

Bourdieu, P. (1984). Distinction: A Social Critique on the Judgement of Taste. London: Routledge \& Kegan Paul.

Boykoff, M., \& Boykoff, M. (2004). Balance as bias: Global warming and the US prestige press. Global Environmental Change, $14,125-136$.

Brown, P. (1996). Global Warming: Can Civilization Survive? London: Blandford.

Bucchi, M. (1998). Science and the Media: Alternative Routes in Scientific Communication. London: Routledge.

Burgess, J. (1985). News from nowhere: The press, the riots and the myth of the inner city. In J. Burgess \& J. R. Gold (Eds.), Geography, the Media and Popular Culture (pp. 180-220). London: Croom Helm.

Burgess, J. (1990). The production and consumption of environmental meanings in the mass media: A research agenda for the 1990s. Transactions, Institute of British Geographers, 15 , 139-161.

Burgess, J., Chilvers, J., Clark, J., Day, R., Hunt, J., King, S., et al. (2004). Citizens and Specialists Deliberate Options for Managing the UK's Legacy Intermediate and High Level Radio-Active Waste: A Report of the Deliberative Mapping Trial, June-July 2004. DEFRA. Available online at www.corwm.org.uk and www.deliberative-mapping.org.uk.

Burgess, J., Clark, J., \& Chilvers, J. (in press). Going upstream: Issues arising with UK experiments in participatory science and technology. Sociologia e Politiche Sociali.

Burgess, J., \& Harrison, C. M. (1993). The circulation of claims in the cultural politics of environmental change. In A. Hansen (Ed.), The Mass Media and Environmental Issues (pp. 198221). Leicester: Leicester University Press.

Burgess, J., Harrison, C. M., \& Filius, P. (1998). Environmental communication and the cultural politics of environmental citizenship. Environment and Planning A, 30, 1445-1460.

Burgess, J., Harrison, C. M., \& Maiteny, P. (1991). Contested meanings: The consumption of news about nature conservation. Media, Culture and Society, 13, 499-519.

Carvalho, A. (2002). Climate in the News. The British Press and the Discursive Construction of the Greenhouse Effect. Unpublished Ph.D. thesis, University College London.

Carvalho, A. (2005). Representing the politics of the greenhouse effect. Discursive strategies in the British media. Critical Discourse Studies, 2, 1-29.

Chapman, G., Kumar, K., Fraser, C., \& Gaber, I. (1997). Environmentalism and the Mass Media: The North-South Divide. London: Routledge.

Chilton, P. (1987). Metaphor, euphemism and the militarization of language. Current Research on Peace and Violence, 10, 7-19.

Corbett, J., \& Durfee, J. (2004). Testing public (un)certainty of science: Media representations of global warming. Science Communication, 26, 129-151.

Corner, J. (2000). "Influence": The contested core of media research. In J. Curran \& M. Gurevitch (Eds.), Mass Media and Society (pp. 376-397). London: Arnold.

Curran, J., \& Gurevitch, M. (Eds.). (2000). Mass Media and Society. London: Arnold.
Dake, K. (1992). Myths of nature-Culture and the social construction of risk. Journal of Social Issues, 48, 21-37.

Douglas, M., \& Wildavsky, A. (1982). Risk and Culture. Cambridge: MIT Press.

Downs, A. (1972). Up and down with ecology: The "issue-attention cycle". Public Interest, 28, 38-50.

Dryzek, J. (1997). The Politics of the Earth: Environmental Discourses. Oxford: Oxford University Press.

Du Gay, P. (Ed.). (1997). Production of Culture/Cultures of Production. London: Sage/Open University.

Fairclough, N. (1995). Media Discourse. London: Edward Arnold.

Fischhoff, B. (1995). Risk perception and communication unplugged: Twenty years of process. Risk Analysis, 12, 137-145.

Gamson, W. (1992). Talking Politics. Cambridge: Cambridge University Press.

Gandy, O. (1982). Beyond Agenda Setting: Information Subsidies and Public Policy. Norwood, NJ: Ablex.

Gans, H. (1979). Deciding What's News: A Study of CBS Evening News, NBC Nightly News, Newsweek and Time. New York: Pantheon.

Habermas, J. (1989). The Structural Transformation of the Public Sphere (T. Burger, Trans.). Cambridge: Polity Press (original work published 1962).

Hajer, M. (1995). The Politics of Environmental Discourse: Ecological Modernization and the Policy Process. Oxford: Clarendon Press.

Hall, S. (1977). Culture, the media and the "ideological effect". In J. Curran, M. Gurevitch, \& J. Woollacott (Eds.), Mass Communication and Society (pp. 315-348). London: Edward Arnold.

Hall, S. (1980). Encoding/decoding. In S. Hall, D. Hobson, A. Lowe, \& P. Willis (Eds.), Culture, Media, Language (pp. 128-138). London: Hutchinson.

Hansen, A. (Ed.). (1993). The Mass Media and Environmental Issues. Leicester: Leicester University Press.

Harrison, C. M., Burgess, J., \& Filius, P. (1996). Rationalising environmental responsibilities: A comparison of lay publics in the UK and the Netherlands. Global Environmental Change, $6,215-234$.

Hinchliffe, S. (1996). Helping the earth begins at home: The social construction of socio-environmental responsibilities. Global Environmental Change, 6, 53-62.

Hinchliffe, S. (1997). Locating risk: Energy use, the "ideal" home and the non-ideal world. Transactions, Institute of British Geographers, 22, 197-209.

IPCC (Intergovernmental Panel on Climate Change). (1996). Climate Change 1995. Economic and Social Dimensions of Climate Change. Cambridge: Cambridge University Press.

IPCC (Intergovernmental Panel on Climate Change). (2001). Climate Change 2001. The Scientific Basis. Cambridge: Cambridge University Press.

Irwin, A., \& Wynne, B. (Eds.). (1996). Misunderstanding Science? The Public Reconstruction of Science and Technology. Cambridge: Cambridge University Press.

Johnson, R. (1986). The story so far and further transformations? In D. Punter (Ed.), Introduction to Contemporary Cultural Studies (pp. 277-313). London: Longman.

Krosnick, J., Holbrook, A., \& Visser, P. (2000). The impact of the fall 1997 debate about global warming on American public opinion. Public Understanding of Science, 9, 239-260.

Leggett, J. (2000). The Carbon War: Global Warming and the End of the Oil Era. London: Penguin.

Lincoln, Y., \& Guba, E. (1985). Naturalistic Inquiry. Beverly Hills, CA: Sage.

Lowe, P., \& Morrison, D. (1984). Bad news or good news: Environmental politics and the mass media. Sociological Review, 32, $75-90$.

Macnaghten, P., \& Jacobs, M. (1997). Public identification with sustainable development: Investigating cultural barriers to participation. Global Environmental Change, 7, 5-24. 
Mazur, A. (1998). Global environmental change in the news. International Sociology, 13, 457-472.

McComas, K., \& Shanahan, J. (1999). Telling stories about global climate change. Measuring the impact of narratives on issue cycles. Communication Research, 26, 30-57.

Morley, D. (1986). Family Television. London: Comedia.

Mormont, M., \& Dasnoy, C. (1995). Source strategies and the mediatization of climate change. Media, Culture and Society, 17, 49-64.

Munton, R. (2003). Deliberative democracy and environmental decision-making. In F. Berkhout, M. Leach, \& I. Scoones (Eds.), Negotiating Environmental Change: New Perspectives from Social Science (pp. 109-136). Cheltenham: Edward Elgar.

Myers, G., \& Macnaghten, P. (1998). Rhetorics of environmental sustainability: Commonplaces and places. Environment and Planning A, 30, 333-353.

Myerson, G., \& Rydin, Y. (1996). The Language of Environment: A New Rhetoric. London: UCL Press.

Nelkin, D. (1987). Selling Science: How the Press Covers Science and Technology. New York: W. H. Freeman.

Potter, J. (2003). Discourse analysis and discursive psychology. In P. M. Camic, J. E. Rhodes, \& L. Yardley (Eds.), Qualitative Research in Psychology: Expanding Perspectives in Methodology and Design (pp. 73-94). Washington: American Psychological Association.

Rudig, W. (1995). Public Opinion and Global Warming. Strathclyde Papers on Government and Politics, n. 101, University of Strathclyde.

Schiffrin, D. (1994). Approaches to Discourse. Oxford: Blackwell.

Schoenfeld, A., Meier, R., \& Griffin, R. (1979). Constructing a social problem: The press and the environment. Social Problems, $27,38-61$.

Shanahan, J. (2000). Cycles upon cycles. The evolution of media attention to global climate change. Paper presented at the Climate Change Communication Conference. Waterloo, Canada.

Singer, E. (1990). A question of accuracy: How journalists and scientists report research on hazards. Journal of Communication $40,102-116$.

Slovic, P. (2000). The Perception of Risk. London: Earthscan.
Smith, J. (Ed.). (2000). The Daily Globe: Environmental Change, the Public and the Media. London: Earthscan.

Sparks, C. (1987). The readership of the British quality press. Media, Culture and Society, 9, 427-455.

Stripple, J. (2000). Climate risk and climate security. Paper presented at the 41st convention of the International Studies Association, Los Angeles.

Trumbo, C. (1996). Constructing climate change: Claims and frames in US news coverage of an environmental issue. Public Understanding of Science, 5, 269-273.

Ungar, S. (1992). The rise and (relative) decline of global warming as a social problem. Sociological Quarterly, 33, 483-501.

Ungar, S. (1995). Social scares and global warming: Beyond the Rio convention. Society and Natural Resources, 8, 443-456.

Ungar, S. (2000). Knowledge, ignorance and the popular culture: Climate change versus the ozone hole. Public Understanding of Science, 9, 297-312.

van Dijk, T. (1988). News as Discourse. Hillsdale, NJ: Laurence Erlbaum.

van Leeuwen, T., \& Jewitt, C. (Eds.). (2001). Handbook of Visual Analysis. Thousand Oaks, CA and London: Sage.

Wæver, O. (1995). Securitization and de-securitization. In R. Lipschutz (Ed.), On Security (pp. 46-86). New York: Columbia University Press.

Weingart, P., Engels, A., \& Pansegrau, P. (2000). Risks of communication: Discourses on climate change in science, politics, and the mass media. Public Understanding of Science, 9, 261-283.

Wilkins, L. (1993). Between facts and values: Print media coverage of the greenhouse effect, 1987-1990. Public Understanding of Science, 2(1), 71-84.

Wilkins, L., \& Patterson, P. (1990). Risky business: Covering slowonset hazards as rapidly developing news. Political Communication and Persuasion, 7, 11-23.

Wilson, K. (1995). Mass media as sources of global warming knowledge. Mass Communication Review, 22, 75-89.

Wodak, R., de Cillia, R., Reisigl, M., \& Liebhart, K. (Eds.). (1999). The Discursive Construction of National Identity. Edinburgh: Edinburgh University Press.

Zehr, S. (2000). Public representations of scientific uncertainty about global climate change. Public Understanding of Science, 9, 85-103. 